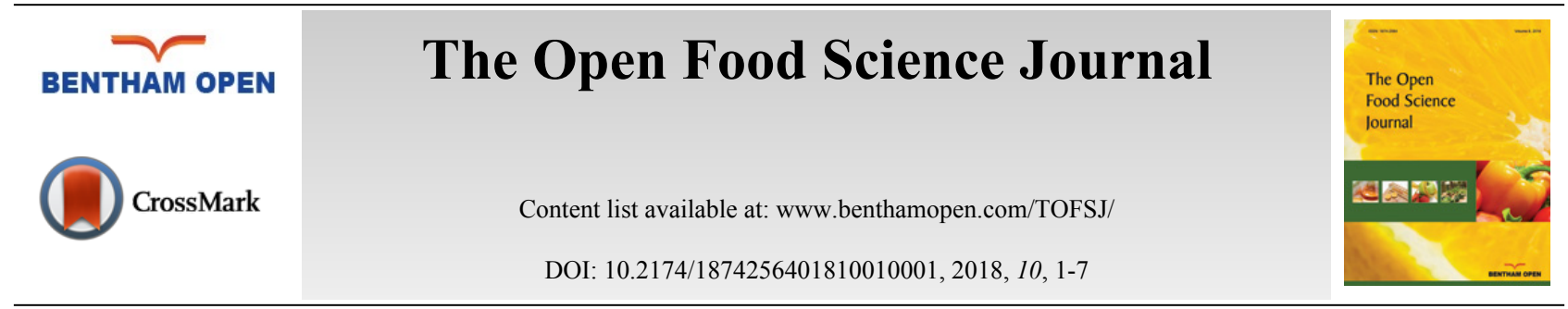

RESEARCH ARTICLE

\title{
Impact of Grinding Procedure on the Yield and Quality of the Extract from Clove Buds Using Supercritical Fluid Extraction
}

\author{
Julio C.F. Johner, Tahmasb Hatami, Pedro I. N. Carvalho and M. Angela A. Meireles* \\ LASEFI/DEA/FEA (School of Food Engineering), UNICAMP (University of Campinas), Campinas, SP, Brazil
}

Received: May 15, 2018

Revised: July 25, 2018

Accepted: August 8, 2018

\begin{abstract}
:
Introduction:

The effects of the grinding procedure on the supercritical fluid extraction (SFE) yields of eugenol, $\beta$-caryophyllene, $\alpha$-humulene, and eugenyl acetate from clove are discussed in detail in this paper.
\end{abstract}

\section{Methods:}

For this purpose, five grinding procedures were employed: 1) continuous 1-min grinding, 2) continuous 2-min grinding, 3) two 1-min grinding periods with 6-min stop in between 4) continuous 4-min grinding, and 5) four 1-min grinding periods with 6-min stops in between. After that, the extractor was filled with $12 \mathrm{~g}$ of milled clove obtained using one of the grinding procedures while the other SFE parameters were kept constant (pressure of 150 bar, temperature of $40^{\circ} \mathrm{C}$, supercritical $\mathrm{CO}_{2}$ flow rate of $1.03 \times 10^{-4} \mathrm{~kg} / \mathrm{s}$, static time of $20 \mathrm{~min}$, and dynamic extraction time of $15 \mathrm{~min}$ ). Then, the composition of the extract was evaluated by gas chromatography (GC).

\section{Conclusion:}

It was found that the grinding procedure has considerable effects on the recoveries of eugenol, $\beta$-caryophyllene, $\alpha$-humulene, and eugenyl acetate from clove, and employing four 1-min grinding periods with 6-min stops in between as the grinding procedure gave the highest content of the aforementioned components in the extract.

Keywords: Supercritical extraction, Grinding procedure, Clove buds, Eugenol, $\beta$-Caryophyllene, $\alpha$-Humulene, Eugenyl acetate.

\section{INTRODUCTION}

The grinding procedure is one of the important factors that has not been sufficiently addressed in the field of SFE. Although the effect of grinding time (GT) has been investigated on the SFE yields of other raw materials, those studies were limited to short GTs. For example, Wilkinson et al. [1] investigated the effect of GT on the SFE yield from soybeans at 483 bar and $80{ }^{\circ} \mathrm{C}$. They placed $60 \mathrm{~g}$ of soybeans in a mechanical grinder for different GTs from 10 to $60 \mathrm{~s}$. They concluded that increasing the GT enhances the extraction yield due to the reduction in particle sizes. The SFE yield increased from approximately $6 \%$ to $22 \%$ as the particle diameters decreased from $0.20 \mathrm{~mm}$ to $0.07 \mathrm{~mm}$. In another study by Yahya et al. [2], the SFE yield from pandan leaf increased up to $50 \%$ after a 30 -s grinding pretreatment step. Hatami et al. [3] investigated the effects of GTs (15 s to $20 \mathrm{~min})$ and mass of raw material in the mill ( $15 \mathrm{~g}$ to $35 \mathrm{~g}$ ) on both the global SFE yield from fennel and the yields of its major compounds, namely, anethol and fenchone. The extractor was subjected to a pressure of $200 \mathrm{bar}$, temperature of $40{ }^{\circ} \mathrm{C}$, and supercritical $\mathrm{CO}_{2}$ flow rate of $1.67 \times 10^{-4} \mathrm{~kg} / \mathrm{s}$ for $10 \mathrm{~min}$. The results showed that a GT of 6 min provided better results than GTs of $15 \mathrm{~s}$ or $20 \mathrm{~min}$ in

\footnotetext{
* Address correspondence to this author at the LASEFI/DEA/FEA (School of Food Engineering), UNICAMP (University of Campinas), Campinas, SP, Brazil; Tel: +55 1932514033; E-mail: maameireles@lasefi.com
} 
terms of contents of anethol and fenchone in the extract. According to this paper [3], although grinding can facilitate SFE by decreasing particles sizes, it also has some disadvantages. One of such drawback is increasing the temperature of the raw material in the mill, which leads to the evaporation of volatile components from the raw material [3]. To avoid this complication and move one-step forward in grinding process, the current study aimed to develop new grinding procedures to cool the raw material and prevent large increases in temperature. Clove bud was selected as the model raw material for this purpose because it is rich in volatile oils, which makes it suitable for evaluating new SFE techniques. Many researchers have studied SFE from clove [4 - 6], and they reported eugenol as its main component. Eugenol shows anti-inflammatory, anti-bacterial, antioxidant, and neuro-protective properties, and it has many applications in cosmetics, food products, and dentistry [7 - 11]. GC-MS analysis showed that there are twenty-two other compounds in the clove oils, and these compounds include $\beta$-caryophyllene, $\alpha$-humulene, and eugenyl acetate [12]. In this paper, the impact of grinding procedure was evaluated on the SFE of clove in terms of the extraction of these four components.

\section{MATERIAL AND METHODS}

\subsection{Sample Preparation}

Clove buds were supplied from a municipal market, called "Temperos Brasil", in Campinas, São Paulo, Brazil, and they were stored in a domestic freezer at $-18{ }^{\circ} \mathrm{C}$. Prior to each grinding experiment, the raw material was removed from the freezer to equilibrate at ambient temperature, $24^{\circ} \mathrm{C}$.

\subsection{Grinding the Raw Material}

The clove buds were ground in a mill (Marconi, model: MA 340, São Paulo, Brazil), and a photo of this mill is available in our previous paper [3]. Its main components are a rotor, a crushing chamber, a collector container, and stainless steel knives (cutting edge). An initial study was performed using the mill to determine the influence of grinding procedure on the physical properties of the clove buds. For this purpose, five grinding procedures were considered (Table 1): 1) continuous 1-min grinding, 2) continuous 2-min grinding, 3) two 1-min grinding periods with 6-min stop in between 4) continuous 4-min grinding, and 5) four 1-min grinding periods with 6-min stops in between. For simplicity, each grinding procedure has been assigned a letter abbreviation as shown in (Table 1). At the end of each grinding procedure, the temperature of the clove buds was measured from the top of the crushing chamber by using an infrared thermometer with an uncertainty of $0.1^{\circ} \mathrm{C}$. The average particle diameters of the milled clove were then determined by screening the milled clove powder through a set of standard sieves with mesh sizes of $12,16,24$, 48, and 80 in a sieve shaker (Bertel, model MAGNETICO, São Paulo, Brazil).

Table 1. Grinding procedures employed in the current study.

\begin{tabular}{|c|c|}
\hline Index & Grinding procedure \\
\hline $\mathrm{A}$ & 1-min grinding \\
\hline $\mathrm{B}$ & 2-min grinding \\
\hline $\mathrm{C}$ & Two 1-min grinding periods with 6-min stops in between \\
\hline $\mathrm{D}$ & 4-min grinding \\
\hline $\mathrm{E}$ & Four 1-min grinding periods with 6-min stops in between \\
\hline
\end{tabular}

\subsection{SFE from Clove}

A schematic diagram of the SFE system used is available in our previous paper [3]. In a typical SFE experiment, the cooling and heating baths are turned on one hour before the extraction to ensure that the system reaches the desired temperature $\left(43{ }^{\circ} \mathrm{C}\right.$ for the heating baths, and $-5{ }^{\circ} \mathrm{C}$ for the cooling baths). The extractor is then charged with $12 \mathrm{~g}$ of milled clove, and the remaining space in the extractor is filled with small glass beads to reduce the $\mathrm{CO}_{2}$ required for pressurizing. Next, the pump is turned on to pressurize the system to the desired pressure (150 bar). The system was kept at that pressure for $20 \mathrm{~min}$ (static time) before opening the exit valve of the extractor. After that, the shut-off and micrometering valves were opened, and the $\mathrm{CO}_{2}$ flow rate was measured by a gas flow meter at the end of the line. The mixture of $\mathrm{CO}_{2}$ and extract is then passed through a micrometering valve, and its pressure drops to the ambient pressure. The extract is trapped in a collection vial, and the overall SFE yield is evaluated by collecting and weighing the extract samples at the end of each run. Each SFE run was performed two times to ensure that the obtained results are reliable. 


\subsection{Chromatographic Analysis}

The contents of eugenol, $\beta$-caryophyllene, $\alpha$-humulene, and eugenyl acetate in the extract were determined using gas chromatography with flame ionization (GC-FID) (SHIMADZU, CG 17-A, Kyoto, Japan) with a fused-silica capillary column ZB-5 (length of $30 \mathrm{~m}$, inner diameter of $0.25 \mathrm{~mm}$, and film thickness of $0.25 \mu \mathrm{m}$, Phenomenex, Torrance, USA). For this purpose, the analyzable solution was obtained by dissolving $5 \mathrm{mg}$ of extract in $1 \mathrm{~mL}$ of ethyl acetate (99.5\% purity, provided by Dinamica, Diadema, Brazil). The carrier gas was helium (99.9\% purity, White Martins, Campinas, Brazil) at a total flow rate of $26 \mathrm{~mL} / \mathrm{min}$ and a column flow rate of $1.11 \mathrm{~mL} / \mathrm{min}$. Split injection was conducted with an injection volume of $1 \mu \mathrm{L}$ and a split ratio of 20 . The injector temperature was $220{ }^{\circ} \mathrm{C}$, the detector temperature was $240{ }^{\circ} \mathrm{C}$, and the initial column temperature was $60{ }^{\circ} \mathrm{C}$. Based on a program defined in our previous publication [3], the column was heated from $60{ }^{\circ} \mathrm{C}$ to $240{ }^{\circ} \mathrm{C}$ at $3{ }^{\circ} \mathrm{C} / \mathrm{min}$, and then held for $2 \mathrm{~min}$. The four main compounds in clove oil were accurately identified by comparison to the retention times of the pure compounds.

\section{RESULTS AND DISCUSSION}

Fig. (1) shows the clove samples, the milled clove before and after extraction, the material distribution inside the mill, and the extract oil. Clove is almost cylindrical in shape, but the milled clove is approximately spherical (A). The distinct differences between the milled material before and after SFE (B and C in Fig. 1) indicate the high performance of the SFE in obtaining the extractable oil. This figure (part D) also shows that the raw material mostly accumulates close to the cutting edges of the mill. Part E of this figure shows that the color of essential oil is yellow (color is one of the indicators of the quality of the essential oil of clove.

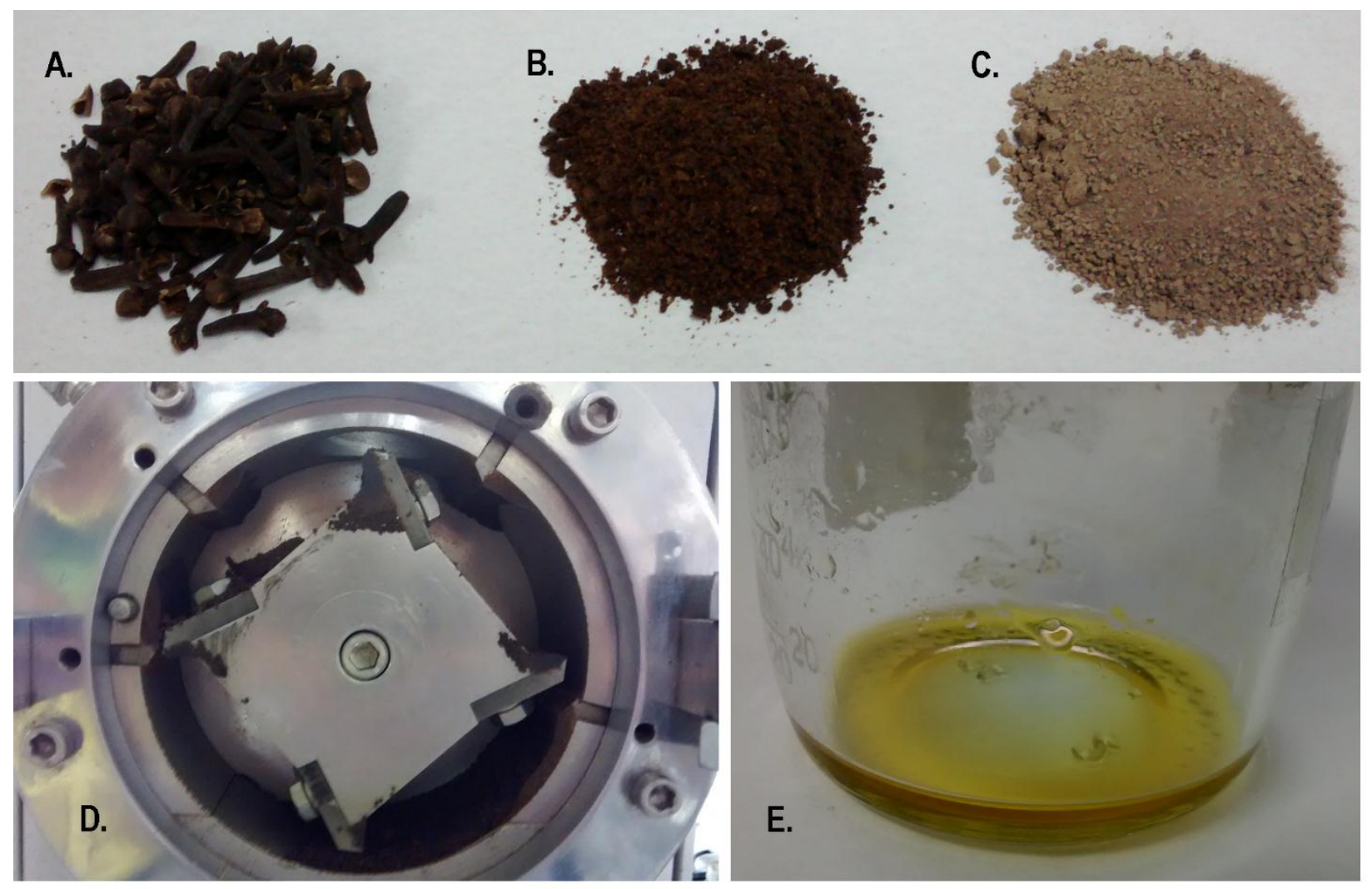

Fig. (1). A schematic of (A) the raw material before grinding, (B) raw material after grinding, (C) raw material after SFE, (D) clove distribution inside the crushing chamber of the mill, (E) and extract oil obtained from clove using SFE.

Fig. (2) shows the SFE yields of eugenol, $\beta$-caryophyllene, $\alpha$-humulene, and eugenyl acetate. The similarities in the trends of the yields of these four components could be explained by the fact that their enthalpies of vaporization under standard conditions are very close to each other, namely, $66.30 \mathrm{~kJ} / \mathrm{mol}$ for eugenol [13], $65.50 \mathrm{~kJ} / \mathrm{mol}$ for $\beta$ caryophyllene [14], $49.4 \mathrm{~kJ} / \mathrm{mol}$ for $\alpha$-humulene [15], and $56.80 \mathrm{~kJ} / \mathrm{mol}$ for eugenyl acetate [16]. As shown in this figure, eugenol had by far the highest yield (9.61 to $11.20 \mathrm{~g} / 100 \mathrm{~g}$ clove), followed by eugenyl acetate (2.09 to $2.55 \mathrm{~g} /$ $100 \mathrm{~g}$ clove), and $\beta$-caryophyllene (1.34 to $1.58 \mathrm{~g} / 100 \mathrm{~g}$ clove). Grinding procedure "E" gave the highest extraction 
yield of the aforementioned components, while grinding procedures " $\mathrm{A}$ " and " $\mathrm{C}$ " gave the lowest yields.
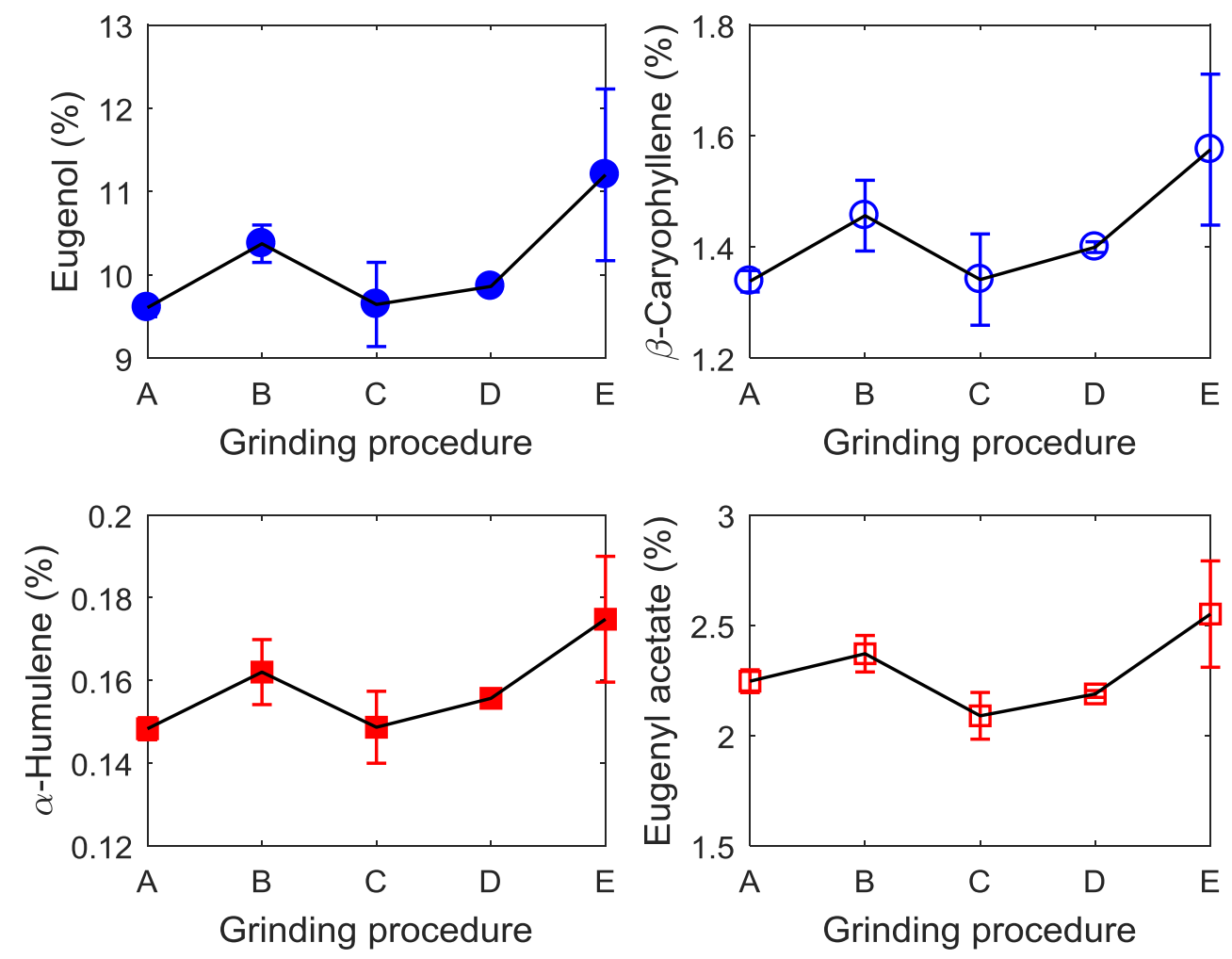

Fig. (2). Effect of grinding procedure on the extraction yield (g / $100 \mathrm{~g}$ clove) of eugenol, $\beta$-caryophyllene, $\alpha$-humulene, and eugenyl acetate from clove by SFE at $150 \mathrm{bar}, 40^{\circ} \mathrm{C}$, and a supercritical $\mathrm{CO}_{2}$ flow rate of $1.03 \times 10^{-4} \mathrm{~kg} / \mathrm{s}$ during a dynamic period of 15 min.

Among the continuous grinding procedures ("A", "B", and "D"), grinding procedure "B" provided the best performance (Fig. 2). The superiority of grinding procedure "B" over " $A$ " and "D" can be attributed to the average diameters and the increasing temperature of the clove in the mill achieved for the various grinding procedures, and these data are shown in (Table 2). It is clear from the table that the temperature was substantially influenced by the grinding procedure, and it increased from $5.5^{\circ} \mathrm{C}$ for " $\mathrm{A}$ " to $10.1^{\circ} \mathrm{C}$ for " $\mathrm{D}$ ". According to Table 2, increasing the GT had two opposing effects on the SFE yield. On one hand, the particle diameter decreased, which had a positive effect on the extraction yield due to enhancing the specific surface area of the particles in the SFE bed. On the other hand, the temperature of material in the mill was increased by increasing GT, and this accelerated the evaporation of the volatile compounds, which tended to reduce the extraction yield of the aforementioned components. These results are in line with those previously published by Hatami et al. [3] on the effect of GT on the SFE yields of anethol and fenchone from fennel. Comparison of the performances of " $B$ " and " $C$ " on one hand and " $D$ " and " $E$ " on the other hand is interesting as each of these pairs have the same particle diameter; $0.39 \mathrm{~mm}$ for "B" and "C" and $0.37 \mathrm{~mm}$ for "D" and "E". Although grinding procedure " $\mathrm{B}$ ", a continuous procedure, provided a higher yield than grinding procedure " $\mathrm{C}$ ", a noncontinuous procedure, comparing " $D$ " and "E" showed the opposite trend; "E" gave a far higher extraction yield of the aforementioned components than "D". This can be justified based on the impact of another important factor, the total GT, which includes the duration of both crushing and stopping. The second column of (Table 2) shows the values of parameter for the whole grinding procedure. It is evident that increasing both the total GT and the temperature increase the evaporation of the volatile components in the raw material. Based on the obtained results, it could be reasonably concluded that for " $\mathrm{B}$ " and " $\mathrm{C}$ ", total grinding time is the key factor; thus, more evaporation occurs in " $\mathrm{C}$ " despite the lower temperature reached. However, for " $\mathrm{D}$ " and "E", the temperature increase is the key factor, which results in "E" providing a higher yield than " $\mathrm{D}$ ". These results show that the total grinding time and the temperature increase might have different effects in different grinding procedures. 
Table 2. The total grinding time (crushing + stopping), temperature increase, and average clove diameter for the various grinding procedures.

\begin{tabular}{|c|c|c|c|}
\hline Grinding procedure & Total time (min) & Temperature raising $\left.\mathbf{(}^{\circ} \mathbf{C}\right)$ & Average diameter $(\mathbf{m m})$ \\
\hline A & 1 & $5.5 \pm 0.9$ & $0.44 \pm 0.01$ \\
\hline B & 2 & $8.4 \pm 0.5$ & $0.39 \pm 0.01$ \\
\hline C & 8 & $7.7 \pm 0.7$ & $0.39 \pm 0.01$ \\
\hline D & 4 & $10 \pm 1$ & $0.37 \pm 0.00$ \\
\hline E & 22 & $8.2 \pm 0.2$ & $0.37 \pm 0.00$ \\
\hline
\end{tabular}

To show the impact of the milling conditions on the extraction yield with respect to the influence of other typical SFE parameters such as temperature, pressure, and $\mathrm{CO}_{2}$ flow rate, it is interesting to compare the results obtained in this study with those reported in the literature. As the major component of clove oil is eugenol, the eugenol recoveries of the various reports can be compared. (Table 3) compared the impact of the developed grinding procedure with the impact of temperature, pressure, extraction time, and $\mathrm{CO}_{2}$ flow rate $(\mathrm{F})$ reported by Chatterjee and Bhattacharjee [17], Wenqiang et al. [12], and Yang et al. [18].

Table 3. The significance of temperature, pressure, extraction time, $\mathrm{CO}_{2}$ flow rate, and grinding procedure on the SFE yield of eugenol from clove.

\begin{tabular}{|c|c|c|c|c|c|c|c|}
\hline $\mathbf{T}\left({ }^{\mathbf{}} \mathbf{C}\right)$ & $\mathbf{P}(\mathbf{b a r})$ & $\mathbf{t}(\mathbf{m i n})$ & $\mathbf{d}(\mathbf{m m})$ & $\mathbf{F}(\mathbf{g} / \mathbf{m i n})$ & $\begin{array}{c}\text { Grinding } \\
\text { procedure }\end{array}$ & $\begin{array}{c}\text { Change of } \\
\text { Eugenol yield }\end{array}$ & Reference \\
\hline $40 \rightarrow 60$ & 250 & 90 & 0.5 & 3.64 & Usual & $112 \%$ & {$[17]$} \\
\hline 60 & $250 \rightarrow 500$ & 90 & 0.5 & 3.64 & Usual & $16 \%$ & {$[17]$} \\
\hline 60 & 250 & $90 \rightarrow 150$ & 0.5 & 3.64 & Usual & $15 \%$ & {$[17]$} \\
\hline $30 \rightarrow 50$ & 300 & 120 & $3 \# \rightarrow 1 \#$ & 3.64 & Usual & $34 \%$ & {$[12]$} \\
\hline 50 & $100 \rightarrow 300$ & 120 & $2 \# \rightarrow 1 \#$ & 3.64 & Usual & $19 \%$ & {$[12]$} \\
\hline $30 \rightarrow 50$ & $100 \rightarrow 300$ & 120 & $1 \#$ & 3.64 & Usual & $24 \%$ & {$[12]$} \\
\hline 40 & 200 & 140 & 0.355 & $0.4 \rightarrow 0.9$ & Usual & $36 \%$ & {$[18]$} \\
\hline 40 & 200 & 140 & 0.355 & $0.9 \rightarrow 1.8$ & Usual & $37 \%$ & {$[18]$} \\
\hline 40 & 150 & 15 & $0.44 \rightarrow 0.37$ & 6.18 & $\mathrm{~A} \rightarrow \mathrm{E}$ & $17 \%$ & Current study \\
\hline
\end{tabular}

Chatterjee and Bhattacharjee [17] studied the extraction of eugenol from clove buds using SFE, and they investigated the effect of temperature $\left(40\right.$ to $\left.130{ }^{\circ} \mathrm{C}\right)$, pressure $(250$ to $500 \mathrm{bar})$, and extraction time (90 to $\left.150 \mathrm{~min}\right)$ using response surface methodology [17]. They charged the extractor with $20 \mathrm{~g}$ of clove powder with a diameter of 0.5 $\mathrm{mm}$ under a constant $\mathrm{CO}_{2}$ flow rate of $2 \mathrm{l} / \mathrm{min}$. Despite obtaining the maximum eugenol yield $(13.292 \mathrm{~g}$ eugenol / $100 \mathrm{~g}$ clove) at $90{ }^{\circ} \mathrm{C}$, they recommended a temperature of $60{ }^{\circ} \mathrm{C}$, a pressure of $250 \mathrm{bar}$, and an extraction time of $90 \mathrm{~min}$ as the optimum operational condition for maximizing the extraction yield of eugenol ( $12.986 \mathrm{~g}$ eugenol / $100 \mathrm{~g}$ clove). The higher yield achieved at an extraction time of 90 min compared to that at 150 min in their work may be due to the depletion of the oil in the clove particles for $\mathrm{t}>90 \mathrm{~min}$, which means that the flow of $\mathrm{CO}_{2}$ not only does not bring any oil to the collection vial but also causes evaporation of the volatile oils from collection vial out the outlet tube. The impacts of temperature, pressure, and extraction time on the yield of eugenol based on the results obtained by Chatterjee and Bhattacharjee [17] are shown in the first three rows of Table 3. As shown in this table, increasing the temperature from 40 to $60{ }^{\circ} \mathrm{C}$ increases the eugenol yield by $112 \%$, while increasing the pressure from 250 to 500 bar or increasing the extraction time from 90 to 150 min changed the eugenol yield by $16 \%$ and $15 \%$, respectively.

Wenqiang et al. [12] extracted eugenol from clove buds using SFE at a constant $\mathrm{CO}_{2}$ flow rate (2 1/min) and extraction time $(120 \mathrm{~min})$ but at various temperatures $\left(30,40\right.$, and $\left.50{ }^{\circ} \mathrm{C}\right)$, pressures $(100,200$, and 300 bar), and particle sizes (three degree index, 1\#, 2\#, and 3\#). The best operating conditions for maximizing the eugenol yield were a temperature of $50^{\circ} \mathrm{C}$, pressure of $300 \mathrm{bar}$, and particle diameter index of 1 \#. Under these conditions, $13.64 \mathrm{~g}$ eugenol / $100 \mathrm{~g}$ clove was recovered. The data from their study are summarized in the fourth to sixth rows of Table 3. In particular, increasing the temperature from 30 to $50^{\circ} \mathrm{C}$ together with decreasing the particle size of clove from $3 \#$ to $1 \#$ at a constant pressure of 300 bar enhanced the eugenol yield by $34 \%$. It should be noted that particle diameter and grinding procedure are dependent of each other, and they can be combined in one variable (grinding procedure). However, they are both reported in (Table 3) for clarity.

Yang et al. [18] compared traditional SFE to ultrasound-assisted SFE (USFE) for the extraction from clove buds 
with $0.355 \mathrm{~mm}$ mean particle diameter. They evaluated the impacts of static time (10 to $30 \mathrm{~min}$ ), dynamic time (20 to $140 \mathrm{~min})$, temperature $\left(30\right.$ to $\left.50{ }^{\circ} \mathrm{C}\right)$, pressure (100 to $\left.200 \mathrm{bar}\right)$, and $\mathrm{CO}_{2}$ flow rate $(0.4$ to $1.8 \mathrm{~g} / \mathrm{min})$ on the extraction yield. The highest USFE yield of $22.04 \mathrm{~g}$ extract / $100 \mathrm{~g}$ clove buds was obtained at static time of $15 \mathrm{~min}$, dynamic time of $100 \mathrm{~min}$, temperature of $40{ }^{\circ} \mathrm{C}$, pressure of $150 \mathrm{bar}$, and $\mathrm{CO}_{2}$ flow rate of $1.4 \mathrm{~g} / \mathrm{min}$, while the corresponding numbers for the highest SFE yield of $19.06 \mathrm{~g}$ extract / $100 \mathrm{~g}$ clove buds were, respectively, $30 \mathrm{~min}, 140 \mathrm{~min}, 40{ }^{\circ} \mathrm{C}, 200 \mathrm{bar}$, and $1.8 \mathrm{~g} / \mathrm{min}$. The current study, however, only focuses on the impacts of flow rate of $\mathrm{CO}_{2}$ on eugenol yield based on SFE data of their study (the seventh and eighth rows of Table 3). Noticeably, it is assumed in this part of table that the extract composition does not affected by $\mathrm{CO}_{2}$ flow rate. This table reports that increasing the flow rate from 0.4 to 0.9 $\mathrm{g} / \mathrm{min}$ and from 0.9 to $1.8 \mathrm{~g} / \mathrm{min}$ enhanced the eugenol yield by $36 \%$ and $37 \%$, respectively.

A general analysis of the whole data in Table 3 reveals that temperature, in particular, and $\mathrm{CO}_{2}$ flow rate are by far the most important factor in the SFE of eugenol from clove. The impacts of the other factors like pressure and extraction time are comparable to the impact of the grinding procedure in the current study as employing grinding procedure "E" instead of " $A$ " increases the eugenol yield by $17 \%$. Nevertheless, using the grinding procedure to increase the SFE performance offers many advantages over changing the pressure or extraction time including its simplicity and lower costs.

\section{CONCLUSION}

This work highlights the impacts of five grinding procedures (A, B, C, D, and E) on the recoveries of eugenol, $\beta$ caryophyllene, $\alpha$-humulene, and eugenyl acetate in the SFE of clove. GC analysis of the obtained extracts showed that eugenol had by far the highest yield (9.61 to $11.20 \mathrm{~g} / 100 \mathrm{~g}$ clove), followed by eugenyl acetate (2.09 to $2.55 \mathrm{~g} / 100 \mathrm{~g}$ clove), and $\beta$-caryophyllene (1.34 to $1.58 \mathrm{~g} / 100 \mathrm{~g}$ clove). Grinding procedure "E" produced the extract with the highest contents of the aforementioned components, while grinding procedures " $A$ " and " $C$ " gave the lowest yields. Among the continuous grinding procedures ("A", "B", and "D"), grinding procedure "B" provided the best performance in terms of the SFE yield of the main components due to the crossover effect of the GT, which affects the particle size, in one side, and the temperature of material in the mill, in the other side. The experimental results reveal that particles diameter, temperature increases in the mill, and the total GT, which includes the duration of both crushing and stopping, are all critical factors affecting the SFE yields of the key components of clove oil. It was revealed that employing grinding procedure " $\mathrm{E}$ " instead of "A" increases the eugenol yield by $17 \%$, which is very comparable with the impacts of pressure and extraction time in the literature data. The grinding procedure has the potential to play a critical role in SFE for producing higher quality extracts.

\section{ETHICS APPROVAL AND CONSENT TO PARTICIPATE}

Not applicable.

\section{HUMAN AND ANIMAL RIGHTS}

Not applicable.

\section{CONSENT FOR PUBLICATION}

Not applicable.

\section{CONFLICT OF INTEREST}

The authors declare no conflict of interest, financial or otherwise.

\section{ACKNOWLEDGMENTS}

Julio C.F. Johner thanks $C N P q(140287 / 2013-2)$ for the PhD assistantship, and M. Angela A. Meireles thanks $C N P q$ for the productivity grant (302423/2015-0).

\section{REFERENCES}

[1] Wilkinson N, Hilton R, Hendry D, Venkitasamy C, Jacoby W. Study of process variables in supercritical carbon dioxide extraction of soybeans. Food Sci Technol Int 2014; 20(1): 63-70. [http://dx.doi.org/10.1177/1082013212469620] [PMID: 23733823]

[2] Yahya F, Lu T, Santos R, Fryer P, Bakalis S. Supercritical carbon dioxide and solvent extraction of 2-acetyl-1-pyrroline from Pandan leaf: 
The effect of pre-treatment. J Supercrit Fluids 2010; 55(1): 200-7.

[http://dx.doi.org/10.1016/j.supflu.2010.05.027]

[3] Hatami T, Johner JCF, Meireles MAA. Investigating the effects of grinding time and grinding load on content of terpenes in extract from fennel obtained by supercritical fluid extraction. Ind Crops Prod 2017; 109: 85-91. [http://dx.doi.org/10.1016/j.indcrop.2017.08.010]

[4] Wei M-C, Xiao J, Yang Y-C. Extraction of $\alpha$-humulene-enriched oil from clove using ultrasound-assisted supercritical carbon dioxide extraction and studies of its fictitious solubility. Food Chem 2016; 210: 172-81. [http://dx.doi.org/10.1016/j.foodchem.2016.04.076] [PMID: 27211636]

[5] Zabot GL, Moraes MN, Petenate AJ, Meireles MAA. Influence of the bed geometry on the kinetics of the extraction of clove bud oil with supercritical $\mathrm{CO}_{2}$. J Supercrit Fluids 2014; 93: 56-66.

[http://dx.doi.org/10.1016/j.supflu.2013.10.001]

[6] Hatami T, Meireles M, Zahedi G. Mathematical modeling and genetic algorithm optimization of clove oil extraction with supercritical carbon dioxide. J Supercrit Fluids 2010; 51(3): 331-8. [http://dx.doi.org/10.1016/j.supflu.2009.10.001]

[7] Tsai T-H, Huang W-C, Lien T-J, et al. Clove extract and eugenol suppress inflammatory responses elicited by Propionibacterium acnes in vitro and in vivo. Food Agric Immunol 2017; 28(5): 916-31.

[http://dx.doi.org/10.1080/09540105.2017.1320357]

[8] Prasad SN, Muralidhara . Neuroprotective efficacy of eugenol and isoeugenol in acrylamide-induced neuropathy in rats: Behavioral and biochemical evidence. Neurochem Res 2013; 38(2): 330-45. [http://dx.doi.org/10.1007/s11064-012-0924-9] [PMID: 23161090]

[9] Bachiega TF, de Sousa JPB, Bastos JK, Sforcin JM. Clove and eugenol in noncytotoxic concentrations exert immunomodulatory/antiinflammatory action on cytokine production by murine macrophages. J Pharm Pharmacol 2012; 64(4): 610-6. [http://dx.doi.org/10.1111/j.2042-7158.2011.01440.x] [PMID: 22420667]

[10] Devi KP, Nisha SA, Sakthivel R, Pandian SK. Eugenol (an essential oil of clove) acts as an antibacterial agent against Salmonella typhi by disrupting the cellular membrane. J Ethnopharmacol 2010; 130(1): 107-15.

[http://dx.doi.org/10.1016/j.jep.2010.04.025] [PMID: 20435121]

[11] Nagababu E, Rifkind JM, Boindala S, Nakka L. Assessment of antioxidant activity of eugenol in vitro and in vivo.Free Radicals and Antioxidant Protocols. Springer 2010; pp. 165-80. [http://dx.doi.org/10.1007/978-1-60327-029-8_10]

[12] Guan W, Li S, Yan R, Tang S, Quan C. Comparison of essential oils of clove buds extracted with supercritical carbon dioxide and other three traditional extraction methods. Food Chem 2007; 101(4): 1558-64. [http://dx.doi.org/10.1016/j.foodchem.2006.04.009]

[13] Chemeo [homepage on the Internet]. Chemical Properties of Eugenol [updated 2016; cited 2018 Feb 12]. Available from: https://www.chemeo.com/cid/45-324-2/Eugenol

[14] Chemeo [homepage on the Internet]. Chemical Properties of Caryophyllene [updated 2016; cited 2018 Feb 12]. Available from: https:/www.chemeo.com/cid/70-147-1/Caryophyllene

[15] ChemSpider [homepage on the Internet]. a-Humulene [updated 2015; cited 2018 Feb 12]. Available from: http://www.chemspider. com/Chemical-Structure. 4444853.html\#suppInfoTab

[16] Chemeo [homepage on the Internet]. Chemical Properties of Acetyl eugenol [updated 2016; cited 2018 Feb 12]. Available from: https://www.chemeo.com/cid/85-505-7/Acetyl\%20eugenol

[17] Chatterjee D, Bhattacharjee P. Supercritical carbon dioxide extraction of eugenol from clove buds. Food Bioprocess Technol 2013; 6(10): 2587-99.

[http://dx.doi.org/10.1007/s11947-012-0979-2]

[18] Yang YC, Wei MC, Hong SJ. Ultrasound-assisted extraction and quantitation of oils from Syzygium aromaticum flower bud (clove) with supercritical carbon dioxide. J Chromatogr A 2014; 1323: 18-27. [http://dx.doi.org/10.1016/j.chroma.2013.10.098] [PMID: 24290173]

(C) 2018 Johner et al.

This is an open access article distributed under the terms of the Creative Commons Attribution 4.0 International Public License (CC-BY 4.0), a copy of which is available at: (https://creativecommons.org/licenses/by/4.0/legalcode). This license permits unrestricted use, distribution, and reproduction in any medium, provided the original author and source are credited. 